\title{
OBJECT-BASED CLASSIFICATION AND CHANGE DETECTION OF HOKKAIDO, JAPAN
}

\author{
J. G. Park ${ }^{\text {a }}$ I. Harada ${ }^{\text {b }, ~ Y . ~ K w a k ~}{ }^{c}$ \\ ${ }^{a}$ Dept. of Informatics, Tokyo University of Information Sciences, 4-1 Onaridai, Wakabaku, Chiba-city, Japan - \\ amon@rsch.tuis.ac.jp \\ b Dept. of Informatics, Tokyo University of Information Sciences, 4-1 Onaridai, Wakabaku, Chiba-city, Japan - \\ iharada@rsch.tuis.ac.jp \\ c International Centre for Water Hazard and Risk Management (ICHARM), PWRI, 1-6 Minamihara, Tsukuba, Ibaraki, Japan - \\ kwak55@pwri.go.jp
}

Commission VIII, WG VIII/8

KEY WORDS: Object-based, Relative DEM, Paddy, MODIS, SVM

\begin{abstract}
:
Topography and geology are factors to characterize the distribution of natural vegetation. Topographic contour is particularly influential on the living conditions of plants such as soil moisture, sunlight, and windiness. Vegetation associations having similar characteristics are present in locations having similar topographic conditions unless natural disturbances such as landslides and forest fires or artificial disturbances such as deforestation and man-made plantation bring about changes in such conditions. We developed a vegetation map of Japan using an object-based segmentation approach with topographic information (elevation, slope, slope direction) that is closely related to the distribution of vegetation. The results found that the object-based classification is more effective to produce a vegetation map than the pixel-based classification.
\end{abstract}

\section{INTRODUCTION}

The NOAA/AVHRR and Terra/MODIS are one of the most well-known low-resolution sensors. NOAA-N series satellites are a type of polar orbiting meteorological satellite, and 16 of them have been launched by the United States since 1978 with NOAA-19 as the latest in 2009. Terra/MODIS and Aqua/MODIS were launched in 1999 and 2002, respectively, as the successors to NOAA/AVHRR. These two types of MODIS are equipped with 36 bands which are divided into three groups with different spatial resolutions: bands 1 and 2 with a spatial resolution of $250 \mathrm{~m}$, bands 3 to 7 with $500 \mathrm{~m}$, and bands 8 to 36 with $1 \mathrm{~km}$. These satellites have been frequently used to measure meteorological data, such as atmospheric temperature and moisture, distribution of cloud and snow, sea surface temperature, and soil moisture, vegetation and farmland in a widespread area, and natural disasters (floods, droughts, forest fires, etc.) affecting a large area) (Giglio et al, 2003; Roy et al, 2005; Caccamo., et al, 2011; Sun et al, 2011).

In response to a recent demand in more detailed land cover maps, higher resolution satellites have been developed to provide clearer images in which buildings, roads, farmland and even tree stem are detectable. RapidEye and WorldView are examples of such high resolution satellites which are used to investigate changes in forest ecology and urban environment. However, higher resolutions usually mean the larger number of orbiting days. To address this problem, multiple satellites are in simultaneous operation.

In a pixel-based segmentation approach using high resolution satellite imagery, it often happens that an area is not recognized as a single object because multiple types of land cover are detected within the area. For this reason, an object-based segmentation approach has drawn attention in place of a pixelbased approach (Stuckens et al., 2000; Tilton and Lawrence,
2000; Blaschke et al., 2001; Usuda et al., 2005; Van der Sande et al., 2003; Guindon et al., 2004; Wang et al., 2004; Kawagata et al., 2006; Kosaka et al, 2007). An object-based approach divides an image into small segments called image objects and is capable of discerning objects as accurately as visual interpretation by experts. Some studies have even reported that it can detect objects more accurately than the maximumlikelihood method (Kamagata et al., 2006).

Vegetation generally refers to the whole of plant population covering a given area. However, vegetation over a given area is usually not homogeneous; rather, a mixture of different plants cohabits in the area. There is a term, vegetation association, referring to a group of different plants cohabiting in a given location. Vegetation associations are differentiated from one another, depending on species composition, structure, seasonality, physiognomy and other features. Vegetation maps are taking advantage of this classification, using vegetation association to divide vegetation in an area into groups and illustrating their spatial occupation within the area.

Topography and geology are factors to characterize the distribution of natural vegetation. Topographic contour is particularly influential on the living conditions of plants such as soil moisture, sunlight, and windiness (Tamura, 1969). Vegetation associations having similar characteristics are present in locations having similar topographic conditions unless natural disturbances such as landslides and forest fires or artificial disturbances such as deforestation and man-made plantation bring about changes in such conditions.

In 1973, the former Environment Agency of Japan conducted the first National Survey on the Natural Environment (vegetation survey). It was a nationwide survey resulting in a 1/200,000 vegetation map with 362 legends. This survey has since conducted seven times and the results are now recorded on a 1/25,000 map with over 600 legends. However, vegetation 
survey of this type takes time and effort when conducted for a wide area, and thus frequent updating of a vegetation map is not possible.

Many experts have developed a national vegetation map using remote sensing technology, and many of them used a pixelbased segmentation approach such as time-series NDVI and EVI ((Defires et al., 1994; Hansen et al., 2000; Defires et al., 1998; Song et al, 2001; Liu et al., 2003; Yuan et al., 2005). However, many of the resulting maps are actually a land cover map merely reflecting the actual diversity of plants in a given area instead of a vegetation map illustrating the dominance of a vegetation association in an area. This is because, unlike high resolution satellite data, low resolution data, such as MODIS and AVHRR, are not suitable for differentiating objects on the land surface.

To address this problem, we developed a vegetation map of Japan using an object-based segmentation approach with topographic information (elevation, slope, slope direction) that is closely related to the distribution of vegetation. We first divided the land of Japan into the area accessible to human activities such as plains and the area inaccessible to human activities such as mountains. Then, segmentation was applied to the mountainous area by taking slope and slope direction into account. Each resultant segment was additionally segmented based on vegetation phenology in consideration of changes in vegetation due to disturbances. Each of the final segments consisting of a plurality of pixels was considered as an object representing a vegetation association, which is the smallest unit for analysis.

\section{DATA}

\subsection{SRTM90}

This study used SRTM90 for topographic analysis. The NASA Shuttle Radar Topographic Mission (SRTM) has provided digital elevation data (DEMs) for over $80 \%$ of the globe. This data is currently distributed free of charge by USGS and is available for download from the USGS ftp site. The SRTM 90m DEM's have a resolution of $90 \mathrm{~m}$ at the equator.

\subsection{MOD09Q1}

MOD09Q1, which is surface reflectance data, was used to extract vegetation phenology information. MOD09Q1 provides Bands 1 and 2 at 250-meter resolution in an 8-day gridded level-3 product in the Sinusoidal projection. Each MOD09Q1 pixel contains the best possible L2G observation during an 8day period as selected on the basis of high-observation coverage, low-view angle, the absence of clouds or cloud shadow, and aerosol loading. Science Data Sets provided for this product include reflectance values for Bands 1 and 2, and a quality rating. The data were obtained for three years from 2002 to 2004 .

\section{METHOD}

In this study, we introduced the concept of object to represent the smallest unit of vegetation association. An object comprises a plurality of pixels. The size of an object is large when a vegetation association is homogeneous and covers a wide area of a plain or mountain. In contrast, the object size is small in urban areas, where human activities are high. Based on this characteristic, we first divided the land into the area accessible to human activities and the area inaccessible to human activities using DEM and river data.

\subsection{Identification of the area accessible to human activities}

Human activities are high in general on a flat area where cities and towns can be easily built. Agriculture spreads around rivers because it requires a consistent water source. Figure 1 shows a flowchart to identify the area accessible to human activities using DEM and river data. The relative elevation between a given location and the river was calculated as the difference in DEM between the pixel of the location and the pixel adjacent to the river that is determined by tracing the water flow from the location's pixel. Flat areas can be detected by calculating the slope angle of each pixel using a $3 \times 3$ array of DEM data. Figure 2 shows an example of calculating relative elevation. Figures 2a and 2b show DEM and river data, respectively. Figure 2c shows the direction of water flow from each pixel. Water flows from the target pixel to one of its surrounding eight pixels that has the largest elevation difference in comparison with the target pixel. Figure $2 \mathrm{~d}$ shows relative elevation. In this case, water starts from $\operatorname{DEM}(3,1)$ through $\operatorname{DEM}(2,2)$ then to $\operatorname{DEM}(3,3)$, and finally reaches River(3,3). Thus, the relative elevation between $\operatorname{DEM}(3,1)$ and the river is calculated as: $\operatorname{DEM}(3,1)-\operatorname{DEM}(3,3)=8$.

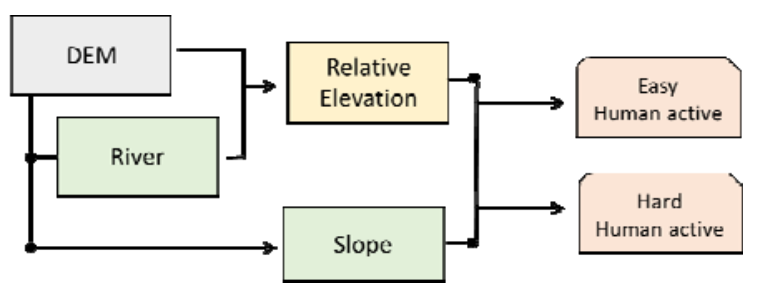

Figure 1. Identification of the area accessible to human activities using DEM

DEM

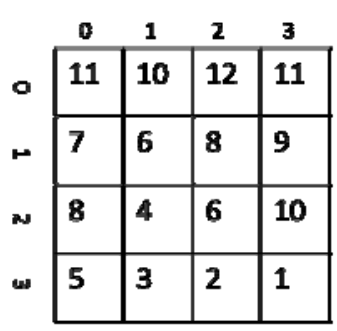

Direction

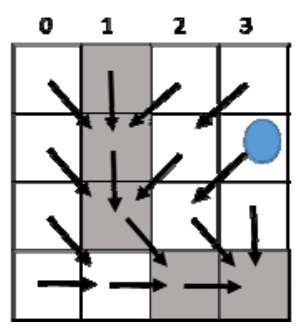

Figure 2. Calculation of relative elevation

\subsection{Application of noise reduction to NDVI data}

This study used time-series NDVI data to extract vegetation phenology information. However, MOD09Q1, 8-day composite imagery, requires noise reduction because it includes much 
cloud. Common strategies taken to reduce the influence of cloud are to lengthen the composite period or to use FFT or Wavelet. These approaches, however, have disadvantages. Longer composite data often make it difficult to differentiate a plant species from one another using phenology. When FFT or Wavelet is performed directly on 8-day composite data, the quality of noise reduction may not be as high as required due to the cloud noise effect. This study thus employed a two-step noise reduction approach, as shown in Figure 3. The first step is the application of the Temporal Window Operation (TWO) method, by which pixels considered to be affected by cloud noise are deleted and linear interpolation is performed. In the second step, the output data after TWO are processed using FFT and then IFFT with a low-pass filter.

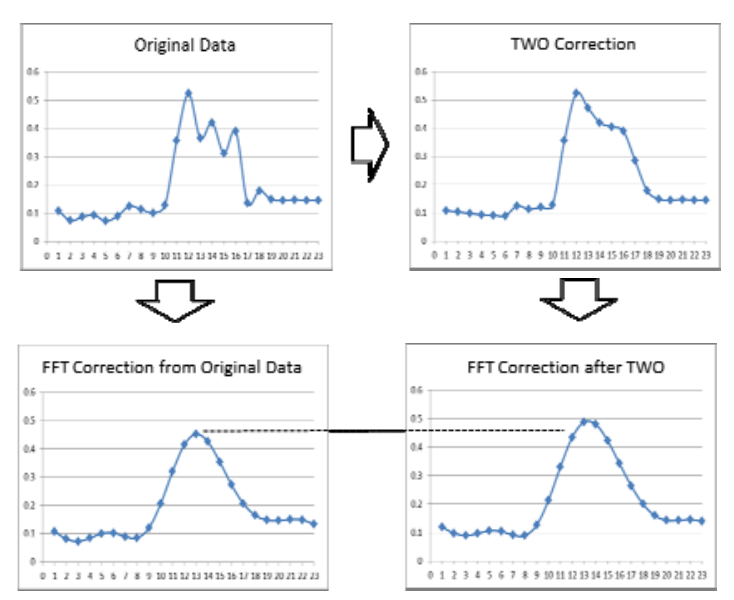

Figure 3. Application of noise reduction using TWO and FFT to time-series NDVI

\subsection{Vegetation phenology information}

Vegetation phenology refers to seasonal developmental stages of plant species, which include, for example, bud burst, flowering and defoliation. Because vegetation phenology varies among different plants, it is used for vegetation classification. Figure 4 shows different types of vegetation phenology information obtained from time-series NDVI, such as Onset, Offset, LOS, L03, L06 Peak, Max, and INDVI.Onset is the time when spring values of the smoothed NDVI curve reached $50 \%$ of the amplitude above the left minimum value.

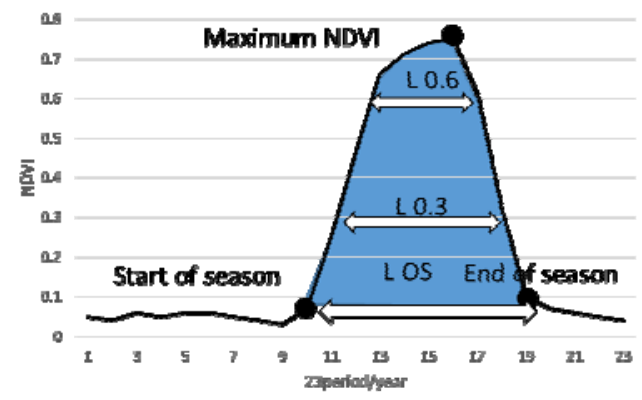

Figure 4. Conceptual image of vegetation phenology

Onset approximates the start of the season. Offset is the time fall values of the smoothed NDVI curve have declined to $50 \%$ above the right minimum value. Offset approximates the end of the season. LOS is the difference between Onset and Offset. LOS period that green forage is readily available. Peak is the time for the maximum smoothed NDVI value. Max is maximum smoothed NDVI value. INDVI is sum of NDVI value from Onset to Offset. L03 and L06 indicate a period in which NDVI reads 0.3 or higher or 0.6 or higher, respectively.

\section{RESULTS}

\subsection{SEGMENTATION}

In this study, segmentation was separately performed on the area accessible to human activities (the plain area) and the area inaccessible to human activities (the mountain area). The plain area, which tends to consist of small divisions due to human activities, was segmented into small objects.
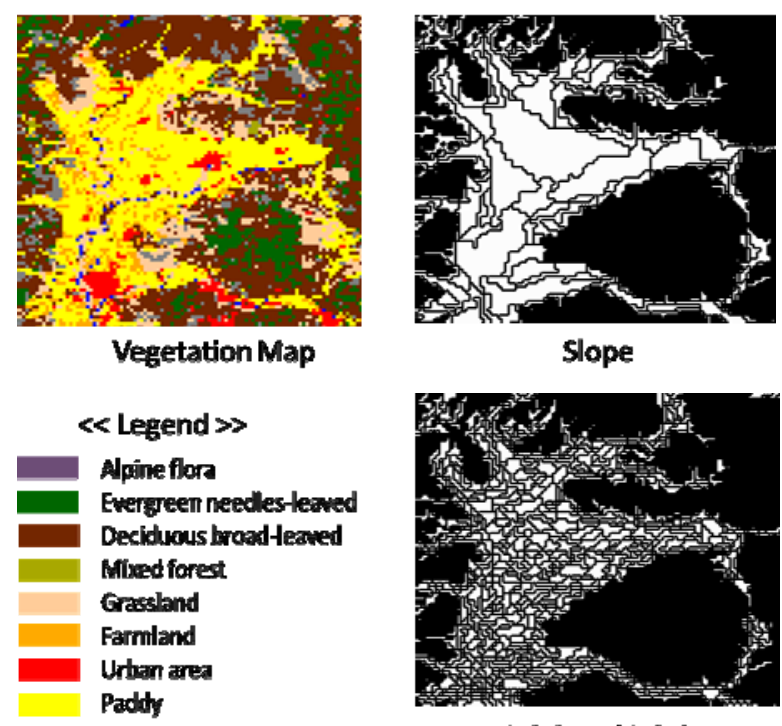

$L 0.3$ and $L 0.6$

Figure 5. Segmentation of the plain area around Asahikawa
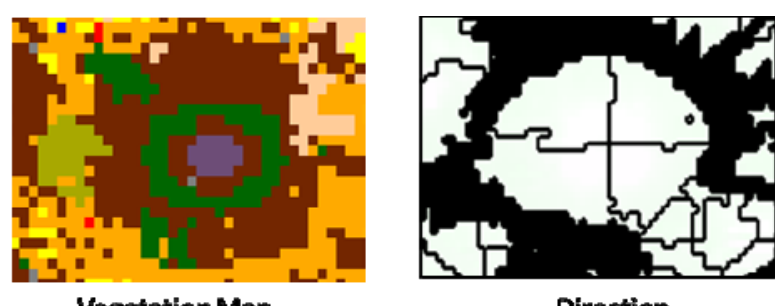

Vegetation Map

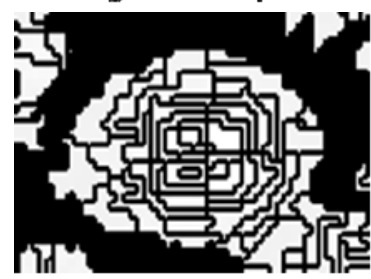

$\mathrm{L} 0.3$ and $\mathrm{L} 0.6$

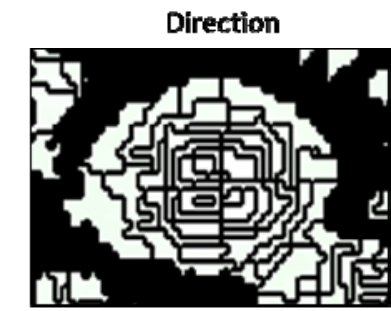

Slope

Figure 6. Segmentation of the mountain area of Mt. Yotei in Hokkaido

Figure 5 shows Asahikawa City of Hokkaido in Japan. Farmland is a dominant land cover around the city, spreading to the foot of the mountains. The segmentation of the plain area was conducted in three steps using first the slope data, then L03 and finally L06. Figure 6 shows a vegetation map of Mt. Yotei $(1,898 \mathrm{~m})$ in Hokkaido. Mt. Yotei is covered with alpine plants 
and deciduous forests around its top, coniferous forests on its hillside, and deciduous forests on its base. The segmentation of the mountain area was first performed in the slope direction, and additionally by using the slope data, L03 and L06 in this order.

\subsection{CLASSFICATION USING SVM}

Figure 7 is the result from vegetation classification performed over Hokkaido. The classification was conducted using the Support Vector Machine, a supervised machine learning classification procedure. Figures $7 \mathrm{a}$ and $7 \mathrm{~b}$ are the results of classification using object-based and pixel-based approaches, respectively. Both figures include the Obihiro area of Hokkaido, where farmland occupies a large space of the area.

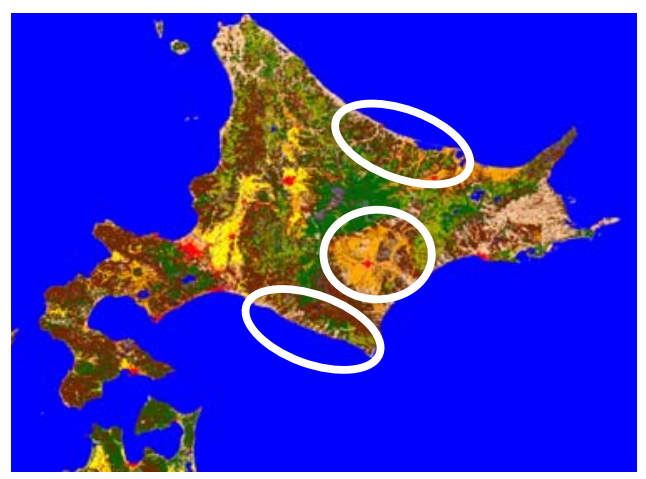

Vegetation Map of Hokkaido

a) Object Based

b) Pixel Based
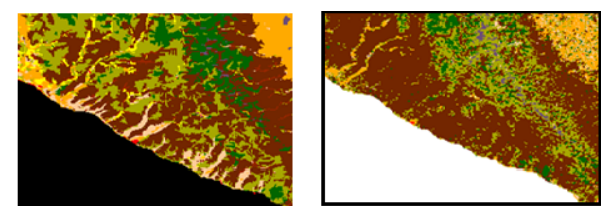

Hidaka area
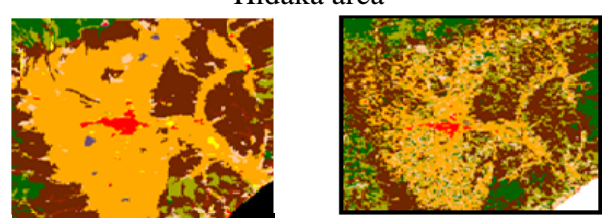

Obihiro area
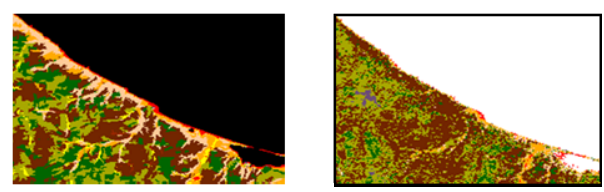

Abashiri area

Figure 7. Comparison of object based classification and pixel based classification

Figure $7 \mathrm{~b}$ shows that the pixel-based approach can clearly detect evergreen forests and deciduous forests scattering in different locations in the area. In contrast, Figure 7a shows only farmland covering the same area, without small patches of different kinds of land cover. Additionally, because the objectbased approach is also designed to use topographic information for classification, the result clearly shows the Hidaka branch of the prefectural office located in southern Hokkaido and the Abashiri branch located in northern Hokkaido.

\section{CONCLUSION}

In this study, we developed a wide-area vegetation map using low-resolution satellite data. A vegetation map is a type of map showing not each kind of plant but the space occupied by vegetation association. Many previous studies used a pixelbased approach and thus the resultant maps show a mixture of different types of land cover over the target areas. This study, instead, used an object-based approach in which segmentation was conducted to produce objects by taking into account topographic conditions that are particularly influential on vegetation distribution. Special care was taken also for the size of an object in consideration of the land use related to human activities. The results found that the object-based classification is more effective to produce a vegetation map than the pixelbased classification.

\section{ACKNOWLEDGEMENTS}

This research was supported in part by the Environment Research and Technology Development Fund (1-1405) of Ministry of Environment, Japan; and by a MEXT Japan grantin-aid for scientific research (No. 26350403).

\section{REFERENCES}

Azzali, S., and Menenti, M., 2000, Mapping vegetation-soilclimate complexes in southern Africa using temporal Fourier analysis of NOAA-AVHRR NDVI data, Int. J. Remote Sensing, vol. 21, pp. 973-996, DOI :10.1080/014311600210380

Caccamo, C., Chisholm, L. A., Bradstock, R. A., Puotinen, M. L., 2011, Assessing the sensitivity of MODIS to monitor drought in high biomass ecosystems, Remote Sensing of Environment, Vol. 115, pp. 2626-2639, DOI: 10.1016/j.rse.2011.05.018

Defries, R. S. and Townshend, J. R. G, 1994, NDVI-derived land cover classifications at a global scale, International Journal of Remote Sensing, Vol. 15, pp. 3567-3586 : DOI:10.1080/01431169408954345

Defries, R. S., Hansen, M. C., Townshend, J. R. G., and Sohlberg, R., 1998, Global land cover classifications at $8 \mathrm{~km}$ spatial resolution: The use of training data derived from Landsat imagery in decision tree classifiers, International Journal of Remote Sensing, Vol. 19, pp. 3141-3168 : DOI:10.1080/014311698214235

Friedl, M.A,McIver, D.K., Hodges, J.C.F., Zhang, X.Y., Muchoney, D., Strahler, A.H., Woodcock, C.E., Gopal, S., Schneider, A., Cooper, A., Baccini, A., Gao, F., Schaaf, C., 2002, Global land cover mapping from MODIS: algorithms and early results, Remote Sensing of Env, vol. 83, pp. 287-302, DOI :10.1016/S0034-4257(02)00078-0

Giglio, L., Descloitres, J., Justice, C. O., Kaufman, Y. J., 2003, An Enhanced Contextual Fire Detection Algorithm for MODIS, Remote Sensing of Environment, vol. 87, pp.273-282, DOI :10.1016/S0034-4257(03)00184-6

Hansen, M. C., Defries, R. S., Townshend, J. R. G. and Sohlberg, R., 2000, Global land cover classification at $1 \mathrm{~km}$ spatial resolution using a classification tree approach, 
International Journal of Remote Sensing, Vol. 21pp. 13311364 : DOI:10.1080/014311600210209

Liu, J. Y., Zhuang, D. F., Luo, D., and Xiao, X., 2003, Landcover classification of China: Integrated analysis of AVHRR imagery and geophysical data, International Journal of Remote Sensing, Vol. 24, pp. 2485-2500 : DOI:10.1080/01431160110115582

Lloyd, D., 1990, A phenological classification of terrestrial vegetation cover using shortwave vegetation index imagery, Int. J. Remote Sensing, vol. 11, pp. 2269-2279, DOI :10.1080/01431169008955174

Muchoney, D., Borak, J., Chi, H., Friedl, M., Gopal, S., Hodges, J., Morrow, N., and Strahler, A., 2000, Application of the MODIS global supervised classification model to vegetation and land cover mapping of Central America, Int. J. Remote Sensing, vol. 21, no. 6 \& 7, pp. 1115-1138

Roy, D. P., Jin, Y., Lewis, P. E., Justice, C. O., 2005, Prototyping a global algorithm for systematic fire-affected area mapping using MODIS time series data, Remote Sensing of Environment, Vol. 97, pp. 137-162, DOI: 10.1016/j.rse.2005.04.007

Song, C., Woodcock, C. E., Seto, K. C., Lenney, M. P., and Macomber, S. A., 2001, Classification and Change Detection Using Landsat TM Data: When and How to Correct Atmospheric Effects, Vol. 75, pp. 230-244 : DOI :10.1016/S0034-4257(00)00169-3

Sun, D., Yu, Y., and Goldberg, M. D., 2011, Deriving Water Fraction and Flood Maps From MODIS Images Using a Decision Tree Approach, IEEE Journal of selected topics in applied earth observations and remote sensing, Vol. 4, pp. 814825, DOI: 10.1109/JSTARS.2011.2125778

Tamura, T., 1969, A series of micro-landform units composing valley-heads in the hills near Sendai. Sci. Rep. Tohoku Univ., 7th Ser. (Geogr.), Vol. 19, pp. 111-127.

Wardlow, B. D., Egbert, S. L., Kastens, J. H., 2007, Analysis of time-series MODIS $250 \mathrm{~m}$ vegetation index data for crop classification in the U.S. Central Great Plains, Remote Sensing of Env, vol. 108, pp. 290-310, DOI :10.1016/j.rse.2006.11.021

Xiao, X., Boles, S., Liu, J., Zhuang, D., Frolking, S., Li, C., Salas, W., Moore, B., 2005, Mapping paddy rice agriculture in southern China using multi-temporal MODIS images, Remote Sensing of Env, Vol, 95, pp. 480-492, DOI :10.1016/j.rse.2004.12.009

Xiao, X., Boles, S., Frolking, S., Li, C., Babu, J. Y., Sala, W., Moore, B., 2006, Mapping paddy rice agriculture in South and Southeast Asia using multi-temporal MODIS images, Remote Sensing of Env, vol. 100, pp. 95-113, DOI :10.1016/j.rse.2005.10.004

Yuan, F., Sawaya, K. E., Loeffelholz, B. C., and Bauer, M., 2005, Land cover classification and change analysis of the Twin Cities (Minnesota) Metropolitan Area by multitemporal Landsat remote sensing, Remote Sensing of Environment, Vol. 98, pp. 317-328 : doi:10.1016/j.rse.2005.08.006

Zhang, X., Friedl, M. A., Schaaf, C. B., Strahler, A. H., Hodges, J.C.F., Gao, F., Reed, B. C., Huete, A., 2003, Monitoring vegetation phenology using MODIS, Remote Sensing of Env, vol. 84, pp. 471-475, DOI :10.1016/S0034-4257(02)00135-9 